\title{
Lingkungan Kerja dan Kepuasan Kerja Dosen
}

\author{
$\operatorname{Ardin} 1^{*}$ \\ ${ }^{1}$ STKIP Pancasakti, Bekasi, Indonesia
}

\section{Article Info}

Article history:

Received: 18 August 2017;

Accepted: 18 October 2017;

Published: 31 October 2017.

Keywords:

Work Environment; Job Satisfaction

\begin{abstract}
The object of this research is to obtain information about the effect of work environment on job satisfaction. It was quantitative research with survei method in The State Islamic Institute Kendari southeast Sulawesi. The research was conducted to all lecturer of The State Islamic Institute Kendari Southeast Sulawesi by using a survei method with path analysis applied in testing hypothesis. There is 76 employees are used as a sample was selected by using Slovin formula. The research conlude: There is a direct positive effect of work environment on job satisfaction The State Islamic Institute of Islam (IAIN) Kendari Southeast Sulawesi.
\end{abstract}

How to Cite:

Ardin, A. (2017). Lingkungan Kerja dan Kepuasan Kerja Dosen. Jurnal Pendidikan Ekonomi \& Bisnis, 5(2), 215-224. https://doi.org/https://doi.org/10.21009/JPEB.005.2.8

* Corresponding Author. ardin.unj88@gmail.com (Ardin) 


\section{PENDAHULUAN}

Perguruan tinggi sejatinya adalah pencetak insan intelektual cerdas. Seluruh elemen penyelenggara Negara di Negeri ini mulai level bawah hingga paling tinggi, tingkat daerah hingga pemerintah pusat dilahirkan dari perguruan tinggi. Faktanya kualitas sumberdaya perguruan tinggi Indonesia masih jauh tertinggal di bawah level perguruan tinggi lain dunia maupun kawasan ASEAN sendiri. Hal ini sesuai dengan data yang dipublish oleh QS Word, Times High Education (THE), dan Academic of Ranking World Universities (ARWU). Hal yang sama juga disampaikan Dr. Ir Basuki Endah Priyatno dalam acara live Kick Andy, bahwa penyebab rendahnya kualitas perguruan tinggi Indonesia adalah kurangnya kerjasama terkait hasil riset perguruan tinggi dengan pihak perusahan atau industri.

Dalam renstra Kementerian Riset, Teknologi dan Pendidikan Tinggi (Kemenristekdikti) 2015-2019, pada tabel capaian kinerja Dikti disebutkan bahwa pada 2014, perguruan tinggi yang masuk top 500 dunia ditargetkan sejumlah 11 perguruan tinggi, realisasinya hanya dua perguruan tinggi. Fakta penurunan peringkat ini menunjukkan bahwa peningkatan kualitas perguruan tinggi Indonesia di bawah peningkatan perguruan tinggi di dunia. Kasus penonaktifan 243 perguruan tinggi yang dilakukan Kemenristekdikti selama 2015 ini, menjadi bukti dan koreksi atas rendahnya kualitas pengelolaan perguruan tinggi Indonesia.

Perguruan tinggi Islam Indonesia juga tidak kalah saing dengan perguruan tinggi Negeri lainnya, walaupun diakui bahwa sebagian besar perguruan tinggi Islam Negeri munculnya belakangan ini. Seiring berjalannya waktu perguruan tinggi Islam Negeri terus berbenah meningkatkan kompetensi dalam berbagai aspek sehingga ada beberapa UIN masuk dalam 10 besar favorit Indonesia. Perguruan tinggi Islam Negeri Indonesia dikenal dengan tiga jenis kategori adalah UIN, IAIN, dan STAIN.

Saat ini seluruh perguruan tinggi Islam Negeri di Indonesia berjumlah 53 yang terdiri dari 11 UIN, 23 IAIN, dan 19 STAIN yang tersebar diseluruh wilayah nusantara. Dari sejumlah perguruan tinggi Islam Negeri yang disebutkan diatas, tidak ketinggalan pula IAIN Kendari Sulawesi Tenggara. Layaknya sebuah organisasi, perguruan tinggi pada umumnya kita percaya bahwa untuk mencapai kualitas unggul harus menciptakan kinerja individual yang baik secara kualitas maupun kuantitas. Sebab pada dasarnya kinerja individual mempengaruhi kinerja tim atau kelompok sehingga akan mempengaruhi kinerja institusi perguruan tinggi secara keseluruhan. Kinerja baik menuntut perilaku yang sesuai dengan harapan organisasi/institusi.

Selama ini peningkatan mutu pendidikan di perguruan tinggi selalu dikaitkan dengan kinerja karyawan dan dosen. Kinerja dosen yang kurang maksimal dalam bekerja perlu dikirkan sisi lain dari dosen yaitu kepuasan dalam bekerja. Jadi kepuasan kerja dosen perlu diprioritaskan agar dosen bisa bekerja secara profesional dalam menjalankan kewajibannya sebagai pendidik.

Kepuasan kerja merupakan sikap perasaan seseorang terhadap pekerjaannya, sikap yang positif terhadap pekerjaannya akan mendorong seseorang melakukan sesuatu seperti tujuan yang diinginkan. Demikian juga dengan dosen yang memiliki kepuasan kerja tinggi akan melakukan pekerjaannya dengan segenap kemampuannya untuk meningkatkan kualitas pendidikan.

Kepuasan kerja merupakan harapan setiap orang dalam sebuah lembaga atau organisasi, seseorang yang memiliki kepuasan kerja lebih akan memusatkan perhatian dan kemampuan dirinya pada pekerjaannya sehingga mendapatkan hasil yang memuaskan. Peningkatan mutu perguruan tinggi tidak terlepas dari peran Rektor sebagai pimpinan sekaligus pengelola kampus dan dosen sebagai pelaksana teknis perkuliahan. Rektor sebagai pimpinan, dituntut memiliki wawasan dan pengetahuan yang luas.

Salah satu kemampuan yang harus dimiliki rektor di antaranya kemampuan 
manajerial, seperti perencanaan, pengorganisasian, pelaksanaan, pengawasan dan juga evaluasi. Peranan rektor yang berkaitan dengan peningkatan mutu atau kualitas sedikitnya ada lima sifat layanan yang harus diwujudkan agar pelanggan puas, yaitu: layanan sesuai dengan yang dijanjikan (reliability); mampu menjamin kualitas pembelajaran (assurance); iklim kampus yang kondusif (tangible); memberikan perhatian penuh pada mahasiswa (emphaty); cepat tanggap pada kebutuhan mahasiswanya (responsiveness).

Sedangkan peranan dosen sebagai pelaksana, dituntut mempunyai kompetensi yang profesional dan dapat memanfaatkan sumberdaya yang ada dalam upaya pencapaian tujuan tridarma perguruan tinggi yang optimal. Oleh karenanya seorang dosen harus memiliki pengetahuan yang berkaitan dengan pembelajaran.

Faktor eksternal yang mempengaruhi kepuasan kerja salah satunya adalah lingkungan kerja. Lingkungan kerja yang baik, sangat dimungkinkan akan memberikan pengaruh yang positif pula dikalangan dosen, yang bisa berpengaruh langsung pada prestasi mahasiswa. Namun, sebaliknya lingkungan yang buruk secara psikologi berdampak langsung dengan perilaku manusia. Efek perilaku seseorang yang dipengaruhi oleh lingkungan merupakan sebuah persoalan serius menurut peneliti untuk dikaji lebih dalam. Perguruan tinggi di negeri ini, tidak sedikit yang dikelola dengan kurang memperhatikan standar pelayanan minimal, tidak kecuali pada lingkungan kerja. Kondisi demikian terjadi juga di Institut Agama Islam Negeri (IAIN) Kendari Sulawesi Tenggara.

Berdasarkan informasi yang peneliti dapatkan di lapangan menunjukkan bahwa mayoritas IAIN Kendari kurang puas dengan pekerjannya. Banyak faktor yang membuat dosen tidak merasa harmonis dan puas dalam bekerja antara lain: lingkungan kerja yang kurang nyaman, motivasi kerja rendah, pihak pengelola kampus belum memberdayakan dosen secara menyeluruh dan merata, banyak dosen yang merasa kurang difasilitasi dalam pengembangan kompetensi, pem- bagian kerja belum merata, struktur organisai belum terkelola secara baik, reward yang rendah, kepemimpinan transformasional yang belum maksimal dirasakan bawahan, kepuasan kerja yang rendah, penyediaan sarana prasarana masih kurang memadai. Hal ini tentunya mendorong timbulnya masalah ketidak puasan dikalangan dosen sebagai pendidik dikampus IAIN Kendari Sulawesi Tenggara.

Kepuasan kerja selalu memperoleh perhatian khusus bagi berbagai kalangan karena suatu alasan penting, bahwa ketika seorang pekerja merasa tidak puas terhadap pekerjaannya, perasaan tanggung jawab terhadap pekerjaannya akan berkurang, suasana akan tidak kondusif, dan beberapa hal negatif akan muncul. Pekerja yang tidak merasa puas cenderung terlibat dalam kemorosotan psikologi dan kemorosotan fisik seperti masuk terlambat, pulang lebih awal, serta tindakan agresif yang berlebihan. Pada sisi lain para pekerja yang puas akan melaksanakan tugasnya dengan baik serta aktif menutupi kekurangan, walaupun bukan pada bagian tugasnya.

Dalam kehidupan berorganisasi, kepuasan kerja biasanya digunakan sebagai dasar ukuran tingkat kematangan organisasi. Salah satu gejala yang menyebabkan kurang baiknya kondisi kerja suatu organisasi adalah rendahnya kepuasan kerja. Sebaliknya kepuasan kerja yang tinggi menunjukan bahwa organisasi telah dikelola dengan baik.

Robert Kreitner dan Angelo Knicki (Knicki, 2008) mengungkapkan bahwa "job satisfaction is defined as a pleasurable emotional state resulting from the appraisal of one's job or job experiences. Job satisfaction is an effective or emosional respone toward various faces of one job." Dari definisi Kreitner dan Knicki dipandang bahwa kepuasan kerja bukanlah sebagai suatu konsep yang satu (unitary concept), tetapi lebih kepada suatu pengertian bahwa seseorang dapat secara relatif terpuaskan dengan satu atau lebih aspek pekerjaan lainnya. Maksud dari aspek pekerjaan lain di sini adalah upah, peluang 
promosi, atasan dan teman bekerja. Selain itu faktor lainpun yang termasuk faktor lingkungan kerja seperti kebijaksanaan, prosedur, dan kondisi kerja. Pada dasarnya kepuasan kerja seseorang terletak pada selisih antara harapan atau keinginan dengan hasil yang telah diperoleh melalui pekerjaannya.

Setiap orang dalam bekerja umumnya menginginkan kepuasan dari tempatnya bekerja yang disebut dengan istilah kepuasan kerja. Tingkat kepuasan seseorang sangat tergantung pada tingkat harapan dan tingkat pencapaian harapan. Kepuasan kerja akan diperoleh apabila ada kesesuaian antara harapan dengan kenyataan yang diperoleh dari tempat kerjanya. Bila kepuasan itu diperoleh maka dirinya akan merasa puas.

Pada dasarnya kepuasan kerja merupakan hal yang bersifat individu karena setiap individu memiliki tingkat kepuasan yang berbeda sesuai dengan nilai-nilai yang dipahaminya. Sumber kepuasan ditentukan oleh beberapa hal seperti pandangan seseorang terhadap sesuatu, tingkat pemenuhan, dan tingkat keinginan seseorang terhadap segala sesuatu di sekelilingnya.

Colquitt, Lepine dan Wesson (2013) menyatakan kepuasan kerja sebagai berikut: Job satisfaction is defined as a pleasurable emotional state resulting from the appraisal of one's job or job experiences. In other words, it represents how you feel about your job and what you think about your job. Employees with high job satisfaction experience positive feelings when they think about their duties or take part in task activities. Employees with low job satisfaction experience negative feelings when they think about their duties or take part in their task activities.

Kepuasan kerja didefinisikan sebagai kondisi emosional yang menyenangkan hasil penilaian dari suatu pekerjaan atau pengalaman pekerjaan seseorang. Hal itu menghadirkan perasaan tentang pekerjaan dan apa yang dipikirkan tentang pekerjaan. Pekerja dengan kepuasan tinggi mengalami hal-hal positif pada saat mereka memikirkan tugas-tugas mereka atau mengambil bagian dalam aktivitas tugas tersebut. Pekerja dengan kepuasan kerja rendah mengalami hal-hal negatif pada saat mereka memikirkan tugas-tugas mereka atau mengambil bagian dalam aktivitas tugas mereka.

Tinggi rendahnya kepuasan kerja seseorang tergantung pada faktor-faktor yang mempengaruhinya. Menurut Colquitt, Lepine, dan Wesson, (2013) terdapat 8 faktor yang mempengaruhi kepuasan kerja, yaitu: (1) Pay (hight salary, secure salary), (2) Promotion (frequent promotions, promotion based on ability), (3) Supervision, (4) Cowoker (enjoyable cowokers, responsible cowokers), (5) Work it self, (6) Altruism (helping others, moral causes), (7) Status (prestige, power over others), (8) environment (comfort, safety). Pendapat ini menunjukkan bahwa: gaji, kenaikan jabatan, supervisi, kerja sama kelompok, pekerjaan itu sendiri, status kerja, sikap mementingkan kerja sama, dan lingkungan kerja merupakan faktor yang dapat mempengaruhi kepuasan kerja para pegawai.

Fred Luthans (2011) (Luthans, 2011) menyatakan bahwa "job satisfaction is a result of employees' perception of how well their job provides those things that are viewed as important". Disini kepuasan kerja adalah hasil persepsi karyawan dari seberapa baik pekerjaan mereka memberikan hal-hal yang dipandang sama pentingnya. Selanjutnya Luthans mengungkapkan ada lima dimensi yang mempengaruhi kepuasan kerja, yaitu: Five job dimensions have been identified to represent the most important characteristics of a job about which employees have affective responses. These are: (1) the work itself, (2) pay, (3) promotion opportunities, (4) supervision, and (5) cowokers.

Bahwa terdapat lima dimensi pekerjaan yang diidentifikasi untuk mewakili karakteristik yang paling penting dari pekerjaan yang memiliki respon akfektif karyawan, yaitu: (1) pekerjaan itu sendiri, (2) gaji, (3) kesempataan promosi, (4) supervisi, dan (5) rekan kerja.

Selanjutnya menurut Schermerhorn

dan Hunt (Schermerhorn, 2010) 
menyatakan, "job satisfaction, an attitude reflecting a person's positive and negative feelings toward a job, co-workers, and the work environment". Yakni kepuasan kerja merupakan sikap yang mencerminkan perasaan positif dan negatif seseorang terhadap pekerjaan, rekan kerja dan lingkungan kerja.

Robbins (Robbins, 2012) mengungkapkan bahwa "job satisfaction is an individual's general attitude toward his or her job, such as the nature of the work, supervision, present pay, promotion opportunities, and relations with co-workers".

Menurut konsep Ini, kepuasan kerja adalah sikap umum terhadap pekerjaan, seperti misalnya bagaimana pegawai bersikap terhadap keadaan pekerjaan, supervisi yang dilakukan oleh pimpinan, gaji yang diterima saat ini, kesempatan untuk dipromosikan dan relasi dengan pegawai yang lain. Dengan demikian kepuasan kerja sangat dipengaruhi oleh situasi kerja, pelaksaan supervisi, gaji yang diperoleh, kemungkinan untuk mengembangkan diri dan serta relasi dengan sesama karyawan.

James L. Gibson et. Al (James, 2012), mengemukakan definisi kepuasan kerja sebagai sikap individu terhadap pekerjaannya bahwa: Job satisfaction is an attitude that individuals have about their jobs. It results from their perception of their job, based on factors of the work environment such as supervisor's style, policies and procedures, work group affilation, working condition and fringe benefit.

Berdasarkan pendapat tersebut dapat disimpulkan bahwa kepuasan kerja adalah sikap individu terhadap pekerjaannya. Hal itu merupakan hasil persepsinya terhadap pekerjaan yang didasarkan pada faktorfaktor yang ada dalam lingkungan pekerjaan, gaya pengawasan, prosedur dan kebijakan, afiliasi kelompok kerja, kondisi kerja dan keuntungan.

Senada dengan Stephen P. Robbins dan Mary Coulter (Robbins, 2012) menyatakan bahwa kepuasan kerja adalah sikap seseorang terhadap pekerjaannya. Job satisfaction refers to a person's general attitude toward his or her job. A person with a high level of job satisfaction has a positive attitude toward his or her job, while a person who is dissatisfaction has negative attitude. Kepuasan kerja mengacu pada sikap umum seseorang terhadap pekerjaannya. Seseorang yang mempunyai kepuasan yang tinggi akan melakukan tindakan positif terhadap pekerjaannya, sebaliknya seseorang yang tidak puas akan menunjukkan tindakan negatif.

Adapun Laurie J. Mullins (Mullins, Management and Organisational Behavior, 2005) memberi definisi kepuasan kerja sedikit berbeda dengan Gibson dan Robbins. Dia menyatakan kepuasan tidak hanya sikap namun juga keadaan internal sseorang seperti perasaan. "Job satisfaction is more of an attitude, an internal state. It could, for example, be associated with a personal feeling of achievemnet, either quantitative or qualitative”. Kepuasan kerja adalah lebih dari pada suatu sikap, tetapi adalah suatu keadaan internal. Misalnya, terkait dengan perasaan pribadi terhadap prestasi, baik kuantitatif atau kualitatif.

Dari penjelasan diatas dapat disintesiskan bawah kepuasan kerja adalah perasaan senang dan tidak senang seseorang terhadap pekerjaan berdasarkan kebutuhannya terpenuhi yang merupakan hasil penilaian pada aspek pekerjaannya, dengan indikator: (1) perasaan terhadap upah/gaji, (2) perasaan terhadap penghargaan, (3) perasaan terhadap supervisi, (4) perasaan terhadap hubungan rekan kerja, (5) perasaan terhadap hubungan atasanbawahan, (6) perasaan terhadap kondisi kerja.

Kepuasan kerja dipengaruhi oleh 8 faktor sebagaimana dijelaskan Colquitt, Lepine, dan Wesson, yaitu gaji, kenaikan jabatan, supervisi, kerja sama kelompok, pekerjaan itu sendiri, status kerja, sikap mementingkan kerja sama, dan lingkungan kerja. Melalui 8 faktor yang di atas, informasi yang peneliti dapatkan dilapangan bahwa sebagian besar dosen kurang puas dengan pekerjannya. 
Banyak hal-hal yang membuat dosen tidak merasa harmonis dan puas dalam bekerja antara lain: lingkungan kerja yang kurang nyaman, motivasi kerja rendah, pihak pengelolah kampus belum memberdayakan para dosen secara menyeluruh dan merata, banyak dosen yang merasa kurang difasilitasi dalam pengembangan kompetensi, pembagian kerja belum merata, struktur organisai belum terkelolah secara baik, reward yang rendah, kepemimpinan transformasional yang belum maksimal dirasakan bawahan, kepuasan kerja yang rendah, penyediaan sarana prasarana masih kurang memadai.

Lingkungan kerja berkaitan dengan keberadaan sarana dan prasarana serta aspek sosial yang mendukung pekerja dalam melak-sanakan pekerjaan. Anggota organisasi atau pegawai yang terlibat dalam pekerjaan yang sama, berbagi tugas bersama, atau menghadapi pekerjaan yang sama memerlukan faktor lingkungan yang dapat mendukung kebersamaan mereka.

Kehidupan suatu organisasi tidak terlepas dari pengaruh lingkungan organisasi, baik lingkungan internal maupun lingkungan eksternal karena organisasi sebagai salah suatu sistem akan selalu berinteraksi dengan lingkungannya. Lingkungan kerja yang dapat mempengaruhi pelaksanaan tugas pegawai adalah lingkungan kerja dimana pegawai itu melaksanakan tugas, hal ini dapat berupa: (1) Iklim organisasi, (2) sarana prasarana, dan (3) lingkungan antar sesama pegawai.

Marilyn J. Davidson and Sandra L. Fielden (2003) mendefenisikan lingkungan kerja adalah, "work environment is a combination of all work place conditions, such as issues of health and safety, employee treatment and behavior and hours of work." Lingkungan kerja adalah kombinasi dari semua kondisi tempat kerja, seperti masalah kesehatan, keselamatan, perlakuan karyawan dan jam kerja.

Lebih lanjut Marilyn J. Davidson and Sandra L. Fielden (Davidson, 2003) "work environment can influence employee attitudes and perceptions, as well as other performance outcomes." Lingkungan kerja dapat mempengaruhi sikap karyawan dan persepsi, serta hasil kinerja lainnya. Motivasi kerja pegawai akan muncul dari lingkungan kerja. Jika lingkungan kerja mendukung maka akan timbul keinginan pegawai untuk melakukan tugas dan tanggung jawabnya secara penuh. Keinginan ini kemudian akan menimbulkan persepsi pegawai dan kreativitas pegawai yang diwujudkan dalam bentuk tindakan. Persepsi pegawai juga dipengaruhi insentif yang diberikan oleh perusahaan.

Jones mengatakan bahwa "the environment is a major contingency for which an organization must plan and to which it must adapt." Lingkungan adalah keseluruhan hal yang harus direncanakan oleh organisasi dan saling beradaptasi. Lebih lanjut Jones (Jones, 2010) mengemukakan: the environment is the set of pressures and forces surrounding an organization that have the potential to affect the way it operates and its ability to acquire scarce resources. Scarce resources include the raw materials and skilled employees an organization needs to produce goods and services; the information it needs to improve its technology or decide on its competitive strategy; and the support of outside stakeholders.

Berdasarkan pendapat Jones tersebut bisa kita ketahui bahwa lingkungan adalah himpunan tekanan dan kekuatan sekitar sebuah organisasi yang memiliki potensi untuk mempengaruhi cara beroperasi dan kemampuannya untuk mendapatkan sumberdaya yang langka. Sumberdaya yang langka termasuk bahan baku dan karyawan yang terampil organisasi perlu untuk memproduksi barang dan jasa, informasi yang dibutuhkan untuk meningkatkan teknologi atau memutuskan strategi kompetitif, dan dukungan dari stakeholder luar.

Ivancevich (Ivancevich, 2008) mengungkapkan mengenai Lingkungan kerja bahwa: work environment describes the working condition of the job, the location in the job and other relevan characteristics of the immediate work environment and have a significan impact on human recourse management. 
Lingkungan kerja adalah kondisi tempat kerja, lokasi kerja, dan karakteristik lain yang relevan dengan tempat kerja dan memiliki tempat pada manajemen sumberdaya. Lebih lengkap diungkapkan oleh Glickman (Glickman, 2010) tentang lingkungan kerja bahwa: work environment is marked by incessant psychological encounters. In just a few minutes of observation, one might see a teacher ask aquestion, reply with a smile to a student's answer, frown at an inattentive student, ask a student to be quiet, put a hand on a student's shoulder, and begin to lecture.

Lingkungan kerja ditandai dengan pertemuan psikologis terus-menerus. Contohnya seperti pertermuan antara pimpinan dan bawahan di kantor. John W. Newstrom (Newstrom, 2015) berpendapat, bahwa "the nature of a worker's environment of the job indirectly influences his or her feelings on the job." Latar belakang seorang pekerja secara tidak langsung akan mempengaruhi suasana di tempat kerja. Maksudnya bahwa kebiasaan dari seorang pekerja akan berpengaruh suasana didalam lingkungan kerja.

Selanjutnya Scherrnerhorn (2010) mengatakan, bahwa: "when we grasp the underlying values of our particular school as a work environment, we can consciously act to reshape the organization into a purposeful collection of individuals who believe that school are for students, for learning, and for improvement rather than for insularity, self protection, and complacency." Berdasarkan pendapat Scherrnerhorn tersebut, dapat disimpulkan bahwa kita memahami nilai-nilai yang mendasari organisasi sebagai lingkungan kerja, kita sadar dapat bertindak untuk membentuk kembali organisasi merupakan tujuan dari individu-individu yang percaya bahwa tempat bekerja adalah menentukan masa depan bukan untuk kepicikan, perlindungan diri, dan lingkungan. Lingkungan kerja yang aman, optimisme dan harapan yang tinggi akan mendukung terciptanya iklim kerja pegawai dikampus yang kondusif untuk membangun budaya akademik yang kokoh.

John R Schermerhom (2010) juga menyatakan, bahwa "the general environment is set of cultural economic, legal political and educational condition found in the areas in which the organization operates." Lingkungan umum adalah himpunan kondisi budaya ekonomi, politik dan pendidikan hukum yang ditemukan di wilayah di mana organisasi beroperasi.

Robbins (2013) mengemukakan tentang lingkungan bahwa: The term external environment refers to factors and forces outside the organization that affect the organization's performance. It includes two component: the specific environment and the general environment.

Berdasarkan pendapat Robbins tersebut diketahui bahwa lingkungan eksternal mengarah pada faktor dan kekuatankekuatan di luar organisasi yang mempengaruhi kinerja organisasi. Hal ini mencakup dua komponen: lingkungan khusus dan lingkungan umum.

John T. Seyfarth (2002) mengemukakan secara psikologis tentang lingkungan kerja, bahwa: "the environment in which people work may either increase or decrease the likehood that they will experience psychological success, when conditions in the work environment prevent them from meeting their expectations, disappointment and frustration follow, self esteerm suffers and individual withdraws emotxmamy and perhaps physicalty by leaving the organization."

Lingkungan di mana orang bekerja, baik dapat meningkatkan atau menurunkan kinerja bahwa mereka akan mengalami kesuksesan psikologis, ketika kondisi di lingkungan kerja yang tidak memenuhi harapan mereka, mendapatkan kekecewaan dan frustasi. Merasa rendah diri dan individu menarik emosional dan mungkin secara fisik dengan meninggalkan organisasi.

Suzanne (2006) mengungkapkan bahwa lingkungan: Environment refers to the layout of the space or room, lighting, color scheme, noise, decorations, and so on. The way in which you arrange your office may send a massage to subordinates that way denote invitation or seclusion. Berdasarkan pendapat Suzanne tersebut dapat diketahui 
bahwa lingkungan mengacu pada tata letak ruang atau ruang, pencahayaan, skema warna, kebisingan, dekorasi dan sebagainya. Cara di mana anda mengatur kantor anda dapat mengirim pesan untuk bawahan yang dapat berupa perintah atau teguran.

Mullins (2005) menyatakan bahwa, "communications are affected by the work environment, by the natura of the task and by technology." Lingkungan kerja adalah berupa seperangkat sarana dan prasarana, komunikasi, dan dukungan teknologi." Batasan ini menunjukkan bahwa faktor lingkungan tidak hanya berupa lingkungan fisik tetapi juga proses komunikasi dan dukungan teknologi. Lingkungan kerja perlu diciptakan sedemikian rupa sehingga mendukung anggota organisasi dalam mencapai tujuan. Dengan kata lain lingkungan kerja harus secara potensial mendukung kekohesifan kelompok dalam melaksanakan pekerjaan yang pada akhimya meningkatkan kinerja organisasi.

Kenneth (1984) menjelaskan juga bahwa: There always be an interaction between the work environment characteristics and the physical and psychological state of the employee. For example, the effect of noise (a work environment characteristic) will depend upon the individual employee's age, upon his or her personal need for privacy and a setting live of distractions. In other words we cannot really consider the work environment without also considering the particular employee.

Dijelaskan bahwa karakteristik lingkungan kerja selalu ada interaksi antara kondisi fisik dan psikologis karyawan. Misalnya, efek kebisingan (karakteristik lingkungan kerja) akan tergantung pada usia karyawan individu, kehilangan tidur, dan tingkat kecemasan. Demikian pula, efektivitas karyawan tertentu yang bekerja di kantor terbuka akan tergantung pada lingkungan atau kebutuhan pribadi untuk privasi dan gangguan suasana secara langsung.

Henwood (2002) menjelaskan tiga elemen lingkungan kerja: (1)The physical environment, which includes physical conditions, tools and technological resources, (2) The human environment, which includes peers, team members and others is the organizational. It also covers the cohesions ang compatibility of the team and the quality ang nature of leadership, (3)The organizational environment, wich includes the organizational structure, and procedures.

Pertama, lingkungan fisik, yang meliputi kondisi fisik, sarana dan sumberdaya teknologi. Kedua, lingkungan manusia, yang mencakup rekan kerja, anggota tim dan orang lain dalam organisasi, hal ini juga mencakup kohesi, kompatibilitas tim dan orang lain dalam organisasi termasuk kualitas dan sifat kepemimpinan. Ketiga, lingkungan organisasi, yang mencakup struktur organisasi dan prosedural.

Lebih lanjut Kenneth mengemukakan, "there are many factors in the work environment that can't either facilitate or inhibit a worker's performance and satisfaction." Ada banyak faktor dalam lingkungan kerja yang baik dapat memfasilitasi atau menghambat kinerja dan kepuasan dari karyawan. Misalnya kebersihan, hubungan antara karyawan dengan pimpinan, tingkat kebisingan dan lain sebagainya. Bahwa kinerja dan gairah karyawan dalam melaksanakan tugasnya sedikit banyak dipengaruhi oleh kondisi material/fisik dan psikologis.

Kondisi material meliputi ventilasi udara, kelembaban udara, cahaya/ penerangan, kebersihan, pewarnaan. Sedang kondisi psikologis meliputi hubungan antar karyawan dan rasa aman, musik, keamanan dan kebisingan. Lingkungan kerja yang baik, aman, sehat akan membawa dampak pada meningkatnya kinerja, mengurangi ketegangan pada mata, terutama ditunjang oleh kondisi kantor yang baik, peralatan kantor yang memadai serta yang terpenting akan lebih meningkatkan semangat kerja karyawan, dan prestasi bagi organisasi.

Lingkungan non fisik, meliputi hubungan yang baik antara pimpinan dan bawahan serta antar dosen maupun pegawai lainya. Adanya hubungan yang harmonis tersebut, maka akan dapat meningkatkan komitmen pegawai terhadap tugas, pekerjaan dan organisasinya. Sehingga dengan 
tumbuhnya komitmen yang baik, kinerja para pegawai pun dapat optimal.

Berdasarkan uraian konsep di atas dapat disintesiskan bahwa lingkungan kerja adalah keadaan tempat kerja baik secara fisik maupun psikis yang dapat mempengaruhi keefektifan melaksanakan pekerjaan seseorang, dengan indikator: (1) kondisi tempat kerja, (2) tingkat kebisingan, 3) penataan ruangan, (4) pembagian jam kerja, (5) fasilitas kerja (6) hubungan antar karyawan.

Memperhatikan kondisi-kondisi yang telah dipaparkan di atas, peneliti memandang perlunya dikaji tentang kepemimpinan transformasional dan lingkungan kerja terhadap kepuasan kerja dosen IAIN Kendari Sulawesi Tenggara.

\section{METODE}

Penelitian ini dilaksanakan di Institut Agama Islam Negeri (IAIN) Kendari Sulawesi Tenggara. Pendekatan penelitian dilakukan secara kuantitatif, dengan metode survei, diukur menggunakan instrumen kuisioner. Analisis data menggunakan statistik parametris dengan path analysis. Penelitian ini dilaksanakan di IAIN Kendari dengan populasi terjangkau sejumlah 94 dosen dengan jumlah sampel 76 menggunakan rumus Slovin. Data dikumpulkan dengan menggunakan instrumen berupa kuesioner yang telah diuji validitas dan reliabilitasnya. Berdasarkan hasil uji instrumen tersebut, variabel kepuasan kerja terdiri dari 31 butir pernyataan valid dengan reliabilitas 0,938. Variabel Lingkungan Kerja terdiri 30 butir pernyataan valid dengan reliabilitas 0,951. Sehingga disimpulkan memenuhi syarat untuk dijadikan pengukur variabel penelitian.

\section{HASIL DAN PEMBAHASAN}

Dari hasil pengujian hipotesis kedua dapat disimpukan bahwa terdapat pengaruh langsung positif lingkungan kerja terhadap kepuasan kerja dengan nilai koefisien korelasi sebesar 0,590 dan nilai koefisien jalur sebesar 0,411. Hal ini menunjukan bahwa lingkungan kerja berpengaruh langsung positif terhadap kepuasan kerja.

Hasil penelitian ini senada dengan pendapat beberapa ahli diantaranya Laurie J. Mullins (2008), "an increasingly important issue affecting job satisfaction and efficiency is the nature of the work environment and workplace facilities." Faktor penting yang mempengaruhi kepuasan dan efisiensi kerja adalah sifat dari lingkungan kerja dan fasilitas kerja itu sendiri. Suasana tempat kerja yang kondusif, kualitas gaya bangunan kantor akan menarik perhatian tersendiri pada akhirnya menghasilkan pekerja inspirasi dan kreatif.

Selanjutnya Robert Kreitner (2013), "Managers can thus enhance employee satisfaction by structuring the work environment and its associated rewards and recognition to reinforce employees' values." Bahwa pemimpin dapat meningkatkan kepuasan kerja dosen melalui tiga hal, pertama pembagian struktur organisasi tepat, menciptakan lingkungan kerja yang kondusif serta pemberian reward sesuai standar upah layak sebagai bagian dalam memperkuat nilai-nilai kerjasama dosen.

Selanjutnya John W. Newstrom (2015), "environmental impact job satisfaction is one part of life satisfaction. The nature of a worker's environment off the job indirectly influences his or her feeling on the job." Lingkungan kerja sangat berpengaruh terhadap kepuasan kerja yang juga merupakan salah satu bagian dari kepuasan hidup. Sifat lingkungan kerja seorang dosen di luar pekerjaannya secara tidak langsung dapat mempengaruhi perasaan individu pada pekerjaan tersebut, yang pada akhirnya bermuara pada kepuasan kerja.

Berdasarkan uraian di atas, maka lingkungan kerja berpengaruh secara langsung positif terhadap kepuasan kerja. Dengan terciptanya suasana lingkungan kerja yang kondusif maka dapat meningkatkan kepuasan kerja dosen.

\section{KESIMPULAN DAN SARAN}

Berdasarkan hasil dan analisis data, maka dapat diambil kesimpulan: Lingkungan Kerja berpengaruh langsung positif terhadap kepuasan kerja. Artinya, lingkungan kerja yang kondusif/nyaman mengakibatkan 
peningkatan kepuasan kerja dosen Institut Agama Islam Negeri (IAIN) Kendari Sulawesi Tenggara.

Berdasarkan kesimpulan di atas, maka saran yang perlu ditindaklanjuti antara lain: (1) Bagi pimpinan IAIN, lingkungan kerja merupakan variabel yang penting diperhatikan agar dosen memiliki kepuasan kerja tinggi. Terciptanya lingkungan kerja yang kondusif, teman sejawat yang penuh dukungan penting untuk diperhatikan sebagai penguatan dalam percepatan pencapaian target perguruan tinggi. Kondisi lingkungan kerja yang kodusif/nyaman sangat perlu menjadi perhatian penting oleh civitas akademika kampus dan dibudayakan agar berdampak pada peningkatan kinerja kepuasan kerja dosen. (2) Bagi dosen IAIN, peningkatan kualitas fasilitas lingkungan kerja harus diikuti peningkatan kinerja yang kompetitif dan profesional dosen, serta bertanggung jawab sehingga kerja-kerja organisasi berjalan sesuai rencana sehingga tercapai target perguruan tinggi. (3) Bagi peneliti lain, agar dapat dijadikan sebagai rujukan dalam rangka penelitian selanjutnya terkait dengan masalah lingkungan kerja dan kepuasan kerja. (4) Bagi masyarakat selaku pengguna output dari perguruan tinggi hendaknya membantu pihak kampus dalam menciptakan suasana kondusif lingkungan kampus.

\section{DAFTAR PUSTAKA}

Davidson, J. M. (2003). Individual Diversity and Psychology in Organizations. England: Jhon Wesley \& Sons.

Glickman, D. C.-G. (2010). Supervision and Instructional Leadership. Boston: Pearson Education.

Ivancevich, K. d. (2008). Organizational Behavior and Manegement (eight ed.). USA: McGraw-Hill International.

James, L. G. (2012). Organizations: Behavior, Structure, Processes. New York: McGraw-Hill.

Jones. (2010). Organizational Theory, Design and Change. New Jersey: Pearson.
Knicki, R. K. (2008). Organizational Behavior (eight ed.). USA: McGraw-Hill International.

Kreitner, R. a. (2013). Organizational Behavior (Seventh ed.). McGraw Hill.

Luthans, F. (2011). Organizational Behavior (12th ed.). New York: McGraw-Hill.

Mullins, J. L. (2005). Management and Organisational Behavior (7th ed.). London: Prentice Hall.

Mullins, J. L. (2008). Management and Organisational Behavior (7th ed.). London: Prentice Hall.

Newstrom, J. W. (2015). Organizational Behavior Human Behavior at Work (Fourteenth ed.). New York: McGrawHill.

Robbins P.Stephen, T. A. (2013). Organizational Behavior (15th ed.). New Jersey: Pearson.

Robbins, P. S. (2012). Management (11th ed.). England: Pearson Education.

Schermerhorn, R. J. (2010). Organizational Behavior (11th ed.). New Jersey: John Wiley.

Suzanne, C. J. (2006). Interpersonal Skill Organizations. New York: McGraw-Hill. 